\section{Questión}

Periodismo / Comunicación ISSN 1669-6581
- Av. $44 \mathrm{~N}^{\circ} 676,1^{\circ}$ piso

CP 1900 - La Plata - Argentina

(i) www.perio.unlp.edu.ar/question

Los tiempos: una mirada desde el aislamiento

Florencia Gandara

DOI: https://doi.org/10.24215/16696581e378

\title{
Los tiempos: una mirada desde el aislamiento
}

\section{The times: a look from isolation}

\section{Florencia Gandara}

Profesora de enseñanza media y superior en Historia (2018) por la Universidad de Buenos Aires (Argentina). Actualmente cursa sus estudios de posgrado en el Instituto de Altos Estudios Sociales de la Universidad Nacional de San Martín (IDAES-UNSAM) y estudia fotoperiodismo en Argra Escuela de la Asociación de Reporteros Gráficos de la República Argentina (ARGRA).

Se especializa en el estudio del pasado reciente argentino, y en particular en la historia de los jóvenes durante la década de 1980 en Argentina. Sus intereses principales son la historia de las juventudes, las experiencias bélicas de los jóvenes oficiales, suboficiales y soldados conscriptos que participaron en la Guerra de Malvinas y los modos en que unos y otros participaron en política en los años posteriores a la guerra.

florencia.gandara@gmail.com

https://orcid.org/0000-0001-7480-2290 
Creo que cada lectorx puede elegir su recorrido. Por eso propongo dos niveles de lectura con tipografía diferenciada.

En esta letra: mi voz, mis reflexiones.

En esta otra: fragmentos del ensayo "El ojo intruso como pedagogía" de Silvia Rivera Cusicanqui, que forma parte del libro Sociología de la imagen. Miradas ch'ixi desde la historia andina.

[Disponible para la descarga gratuita en http://tintalimon.com.ar/descargar.php?libro=978-9873687-10-5 ]

Durante estos días me pregunté muchas veces qué dice mi forma de transitar el aislamiento sobre el paso del tiempo. No pude encontrar algo que sintetice lo que siento. ¿Por qué buscamos ideas únicas, singulares? 


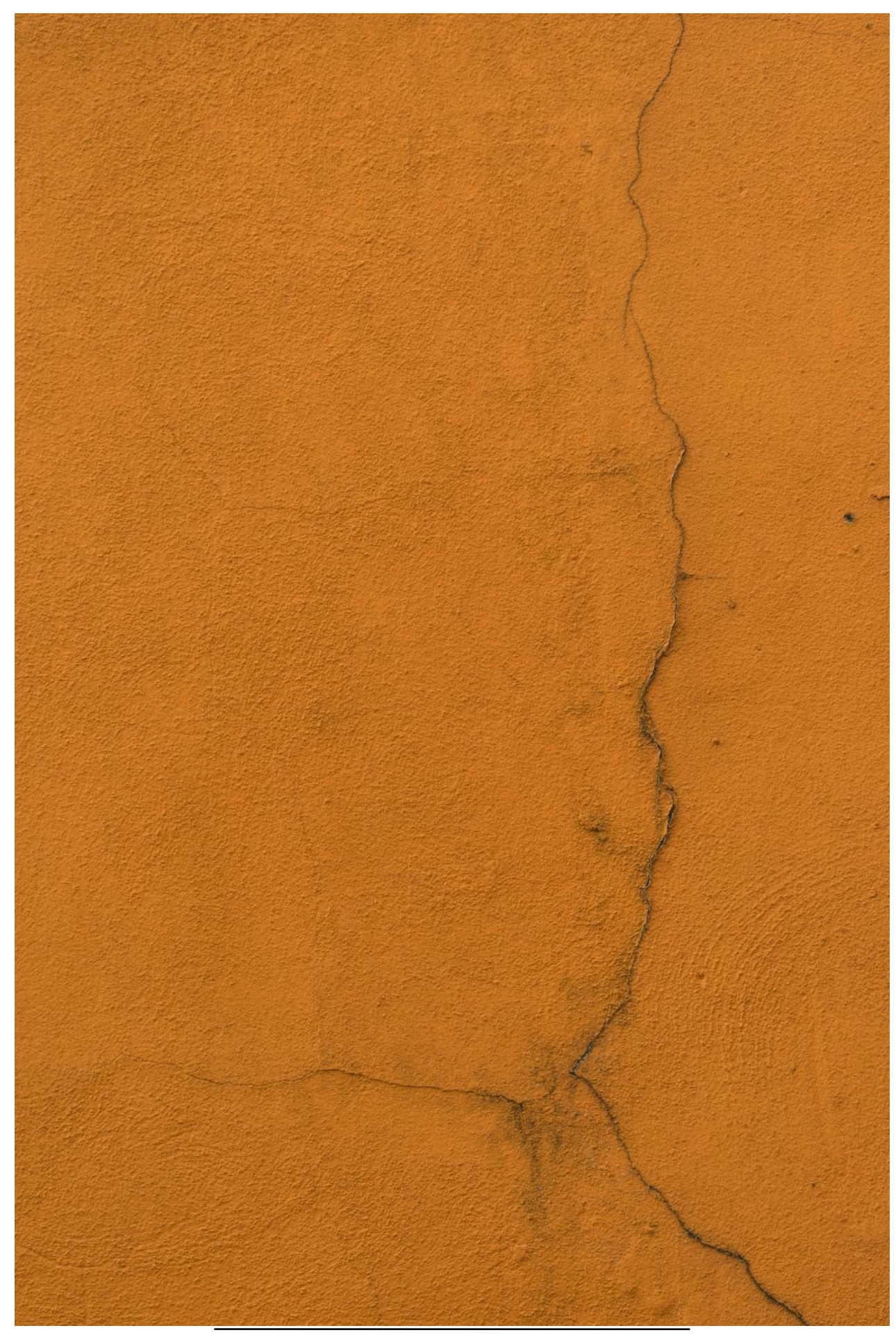

Question/Cuestión, Informe Especial Incidentes III, junio 2020. ISSN 1669-6581

IICom (Instituto de Investigaciones en Comunicación)

Facultad de Periodismo y Comunicación Social

Universidad Nacional de La Plata 
"Ch'ixi literalmente refiere al gris jaspeado, formado a partir de infinidad de puntos negros y blancos que se unifican para la percepción pero permanecen puros, separados. Es un modo de pensar, de hablar y de percibir que se sustenta en lo múltiple y lo contradictorio, no como un estado transitorio que hay que superar (como en la dialéctica), sino como una fuerza explosiva y contenciosa, que potencia nuestra capacidad de pensamiento y acción. Se opone a las ideas de sincretismo, hibridez y a la dialéctica de la síntesis, que siempre andan en busca de lo uno, la superación de las contradicciones a través de un tercer elemento, armonioso y completo en sí mismo." (Cusicanqui, 2015)

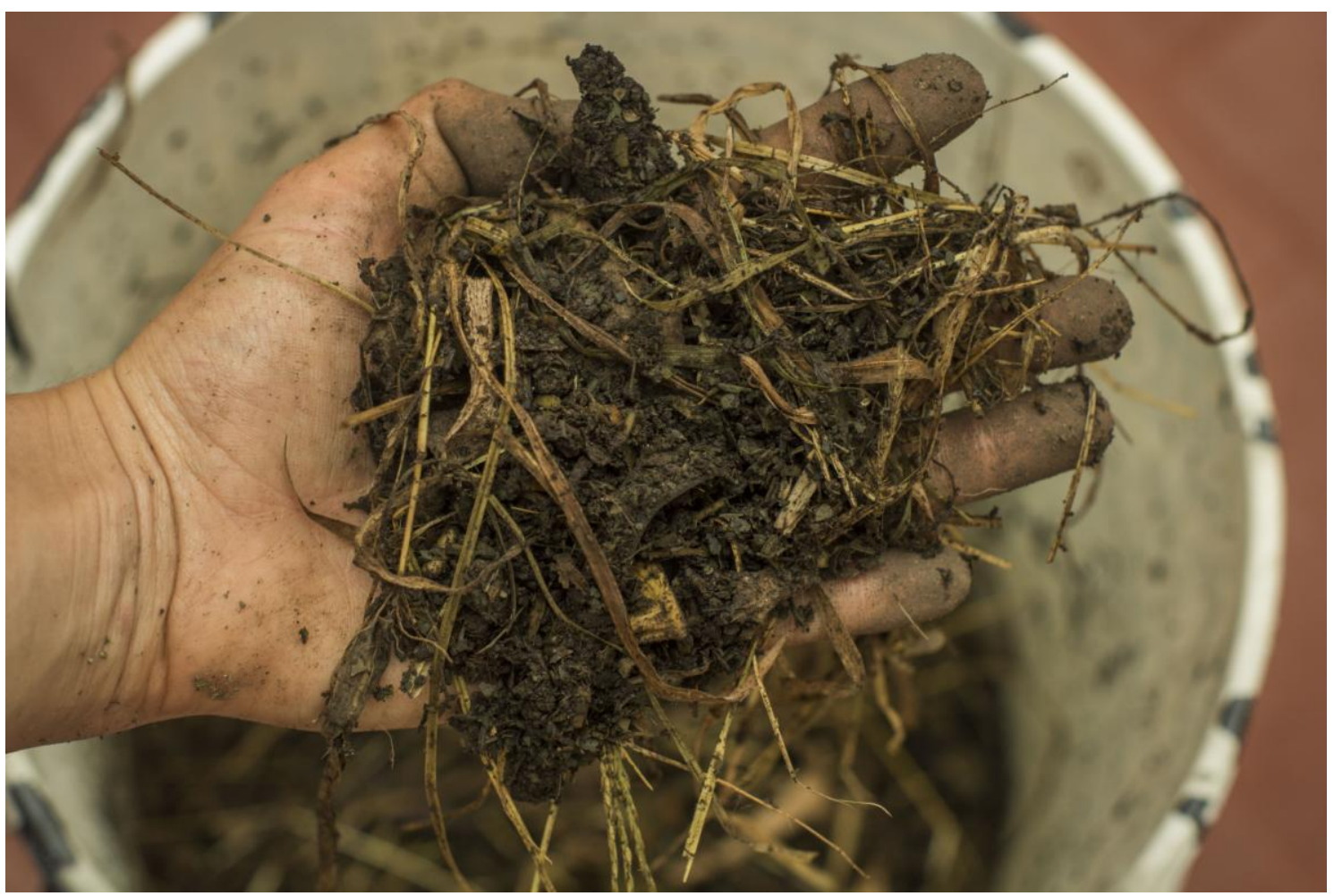

Aunque se escribe en singular, se me hace que el tiempo es múltiple, plural. Yo no soy una sola 
"Nuestra acción reflexiva a través de la mirada trabaja sobre el palimpsesto del presente, sobre las múltiples e irresueltas capas de pasado no digerido, que surgen como "furia acumulada" (Bloch) pero también como bricolage barroco y subversivo"

(Cusicanqui, 2015) 


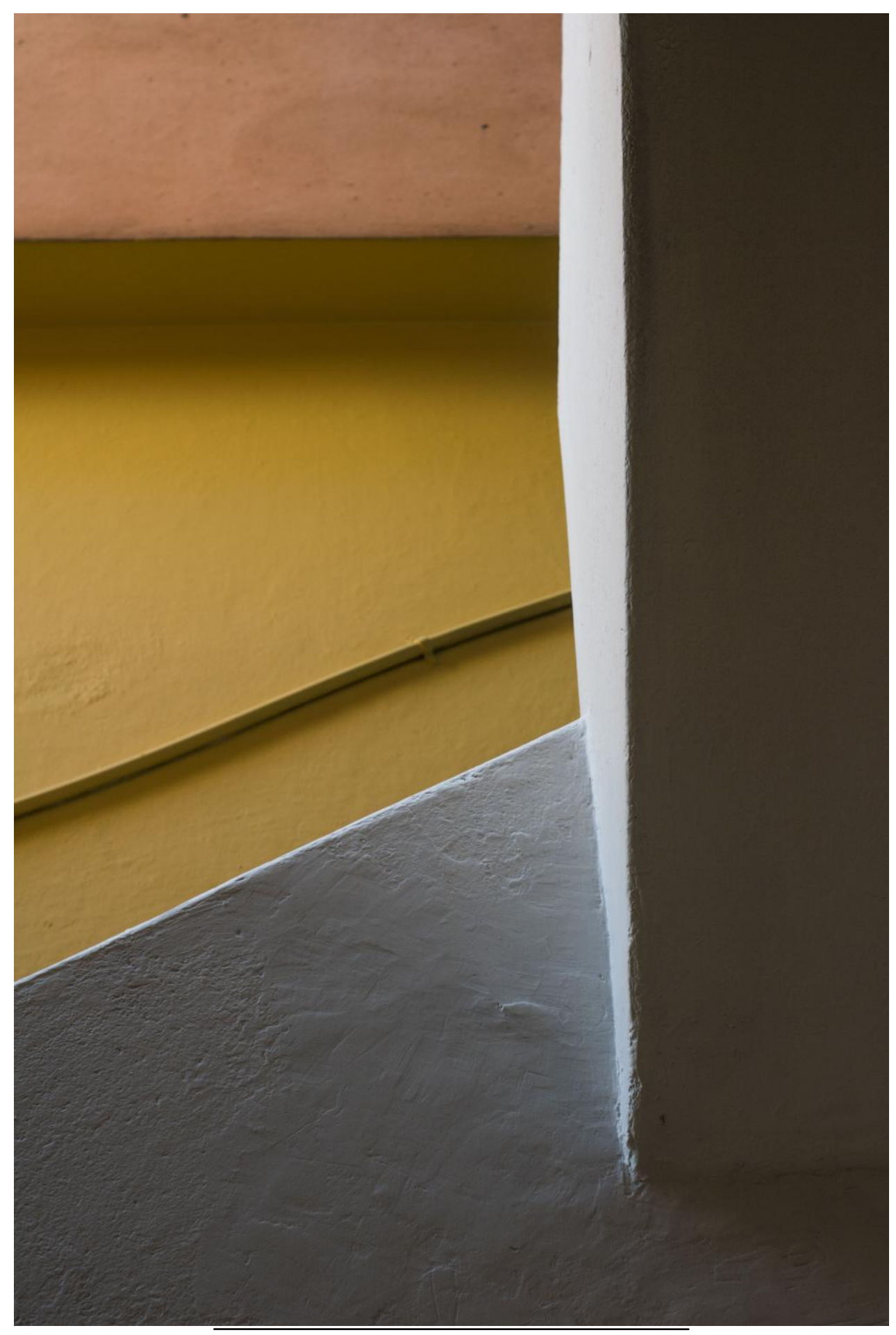


Habito los tiempos del aislamiento y, al observar sus efectos, también los configuro

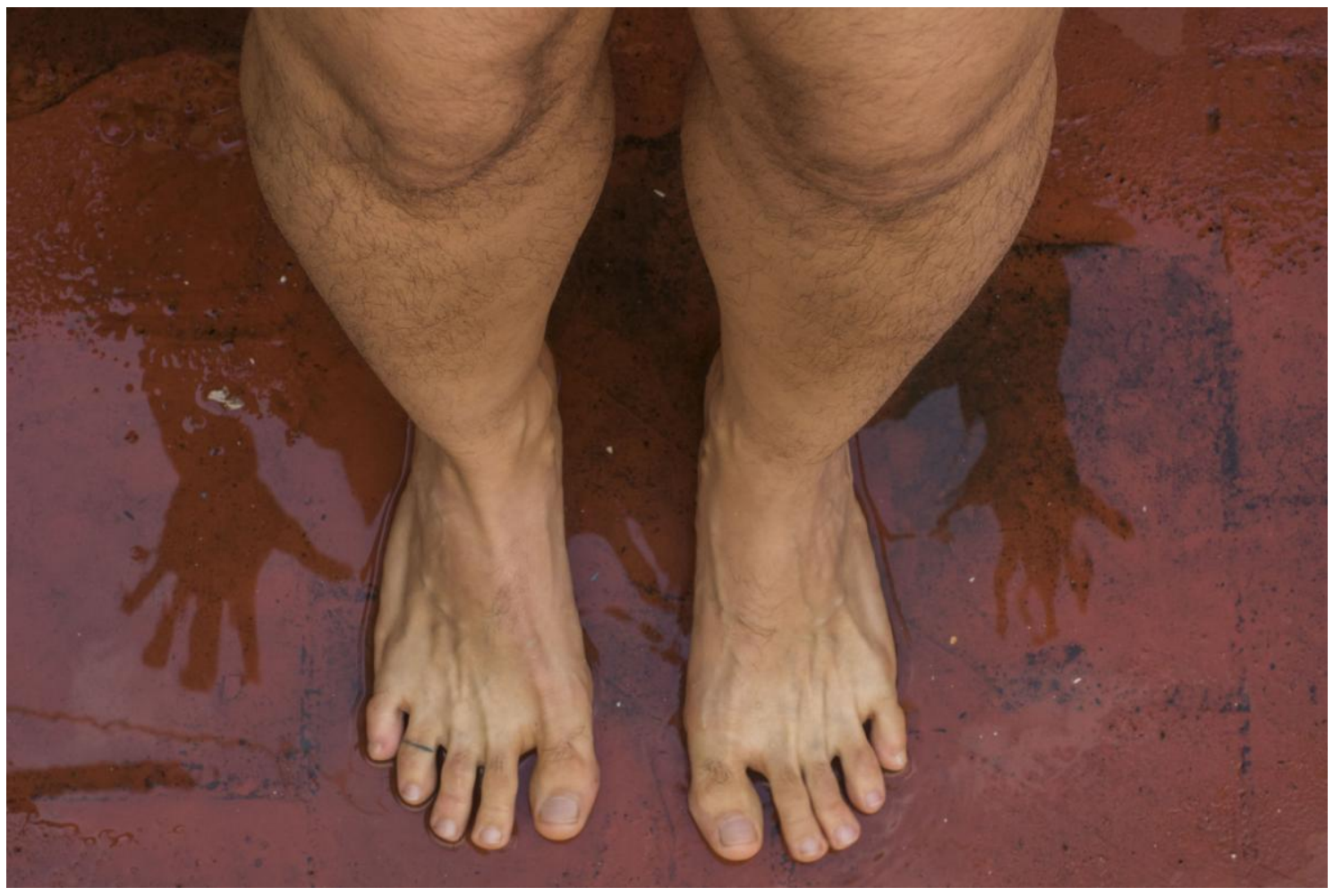


"Tajadas de indio, de salvaje, marcas de heterodoxia y

herejía coexisten con el sentido normal del andar cotidiano"

(Cusicanqui, 2015)

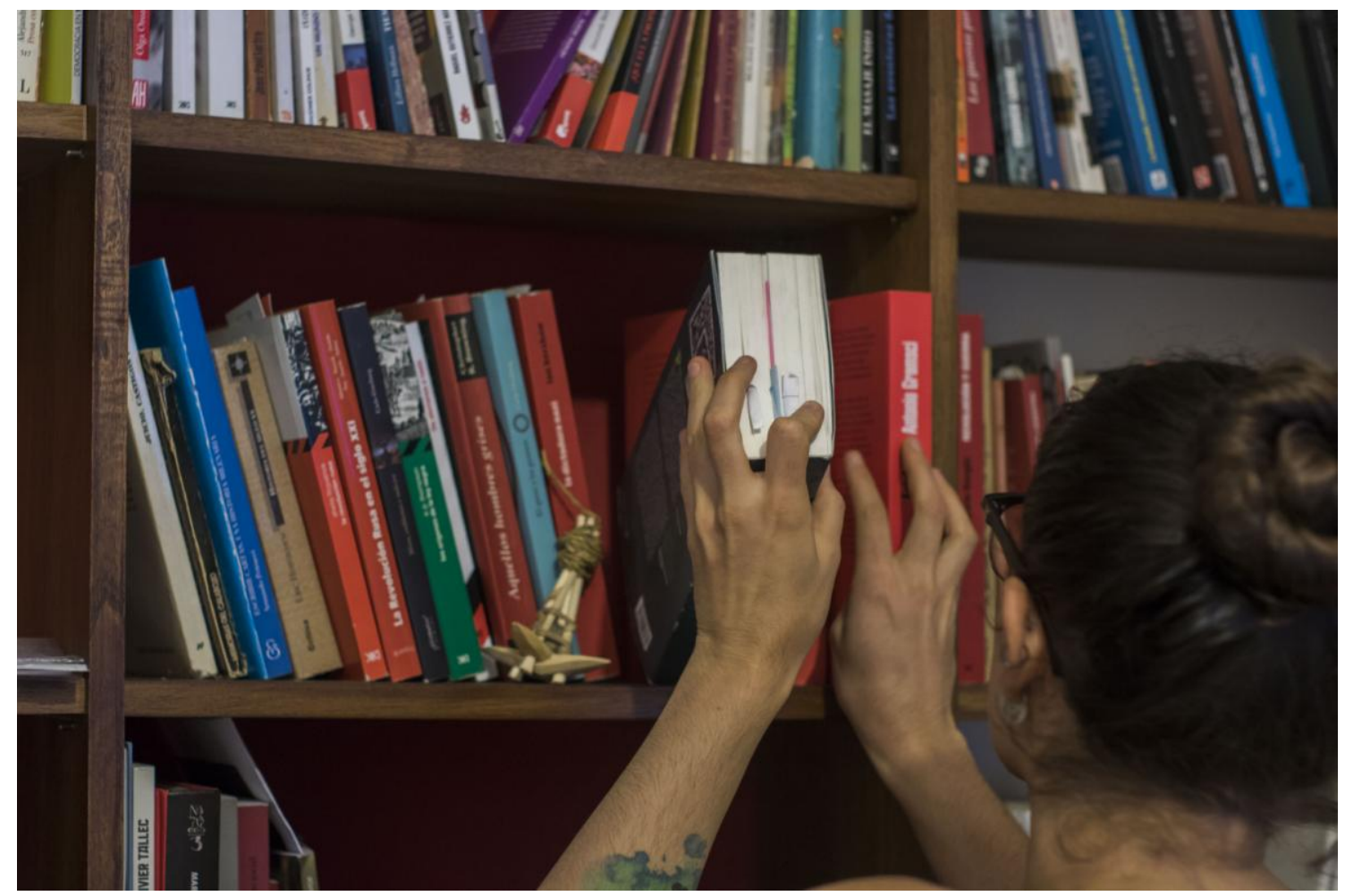




\section{Noto que, como las experiencias, los tiempos sólo existen en los territorios}

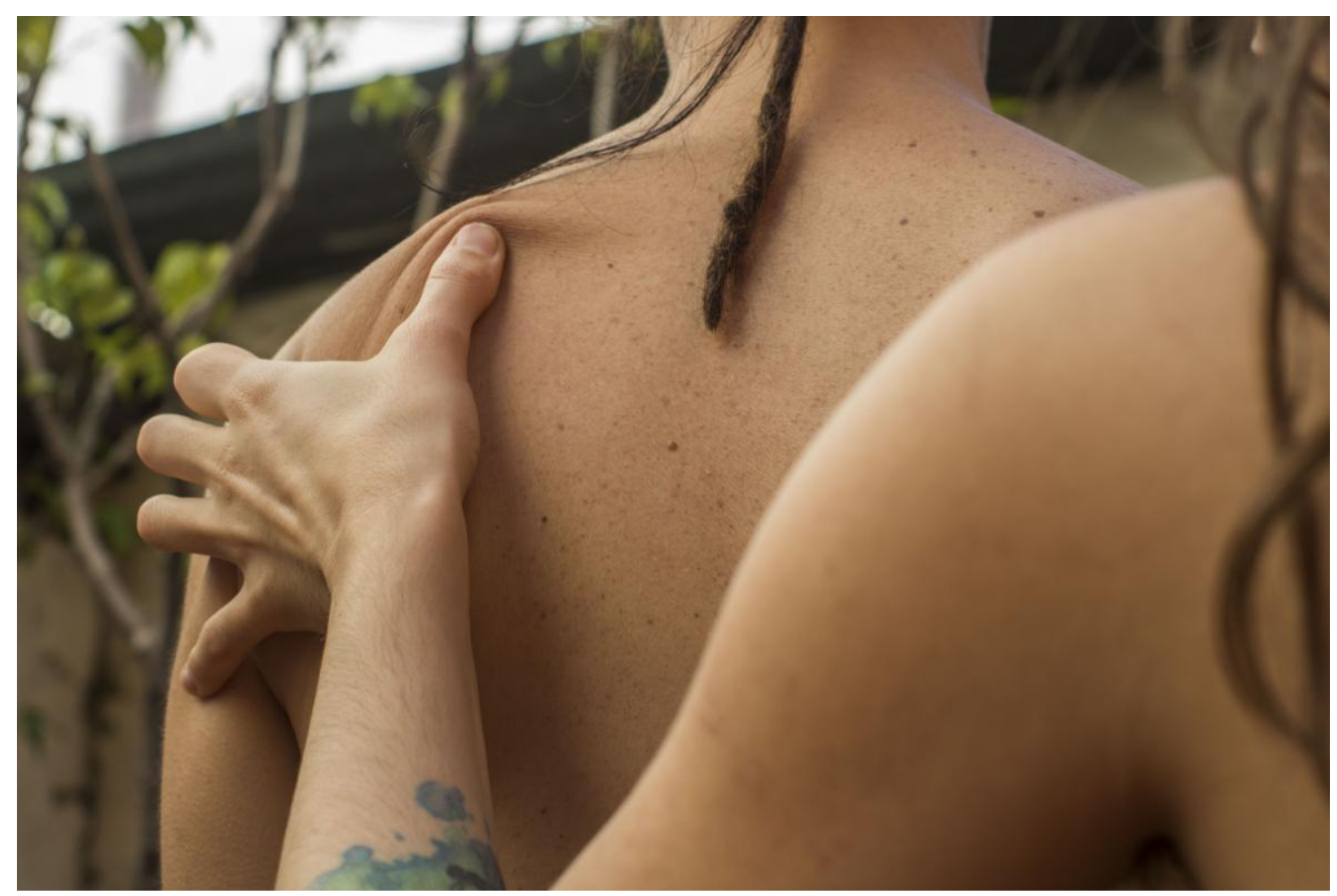

"Esta experiencia nos dio la pauta de que la fotografía podía dejar atrás la incomodidad del "ojo intruso" para convertirse en acompañante cotidiano y casi ritual de nuestra labor (...)"

(Cusicanqui, 2015) 


\section{Sucede que dentro mío conviven tiempos y formas opuestas}

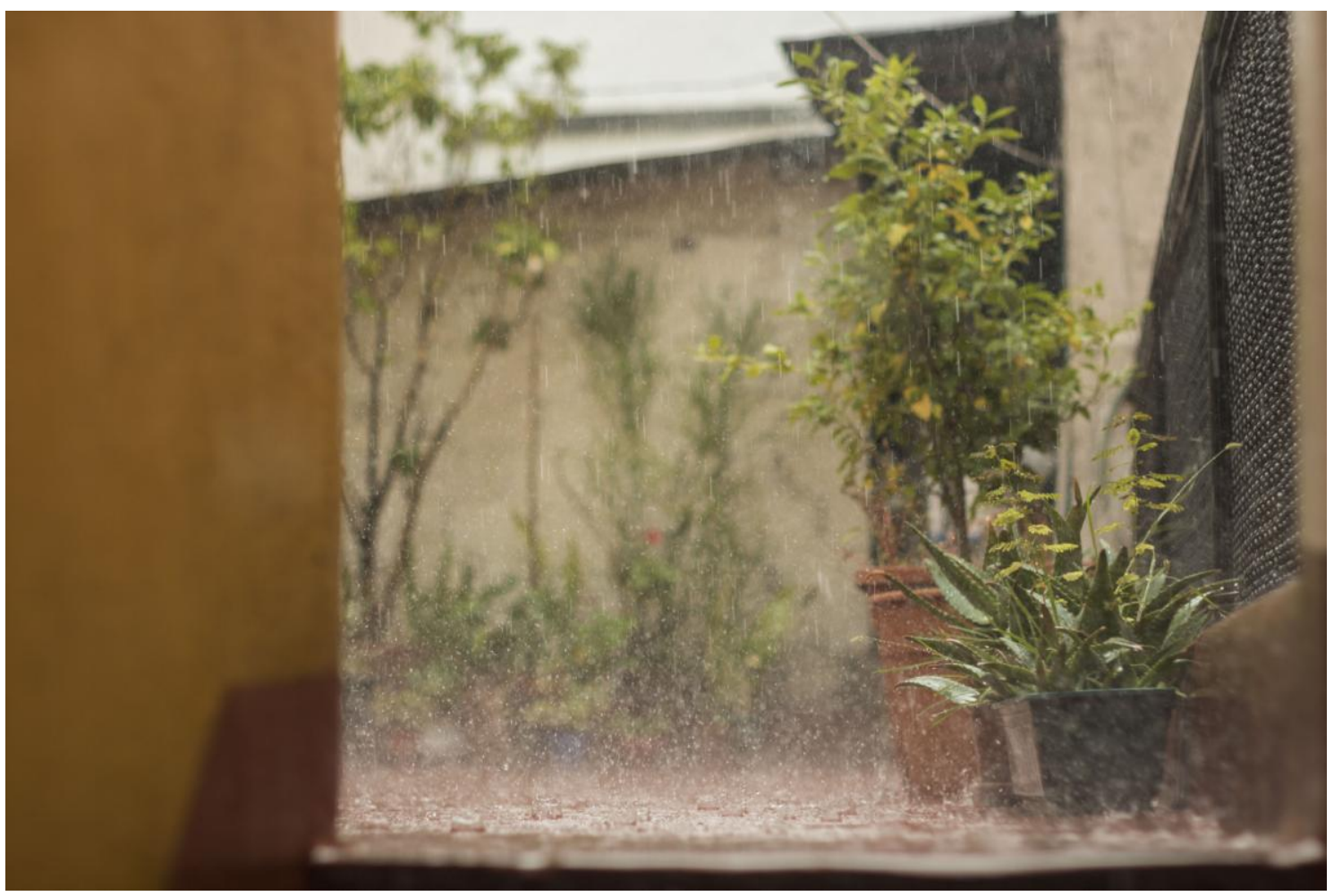

"La epistemología ch'ixi consistirá en abrir y ensanchar ese tercer espacio, entretejiendo a los mundos opuestos en una trama dinámica y contenciosa, en la que ambos se interpenetran sin fusionarse ni hibridizarse nunca. Este taypi o zona de contacto es el espacio ch'ixi de una estructura de opuestos complementarios."

(Cusicanqui, 2015) 


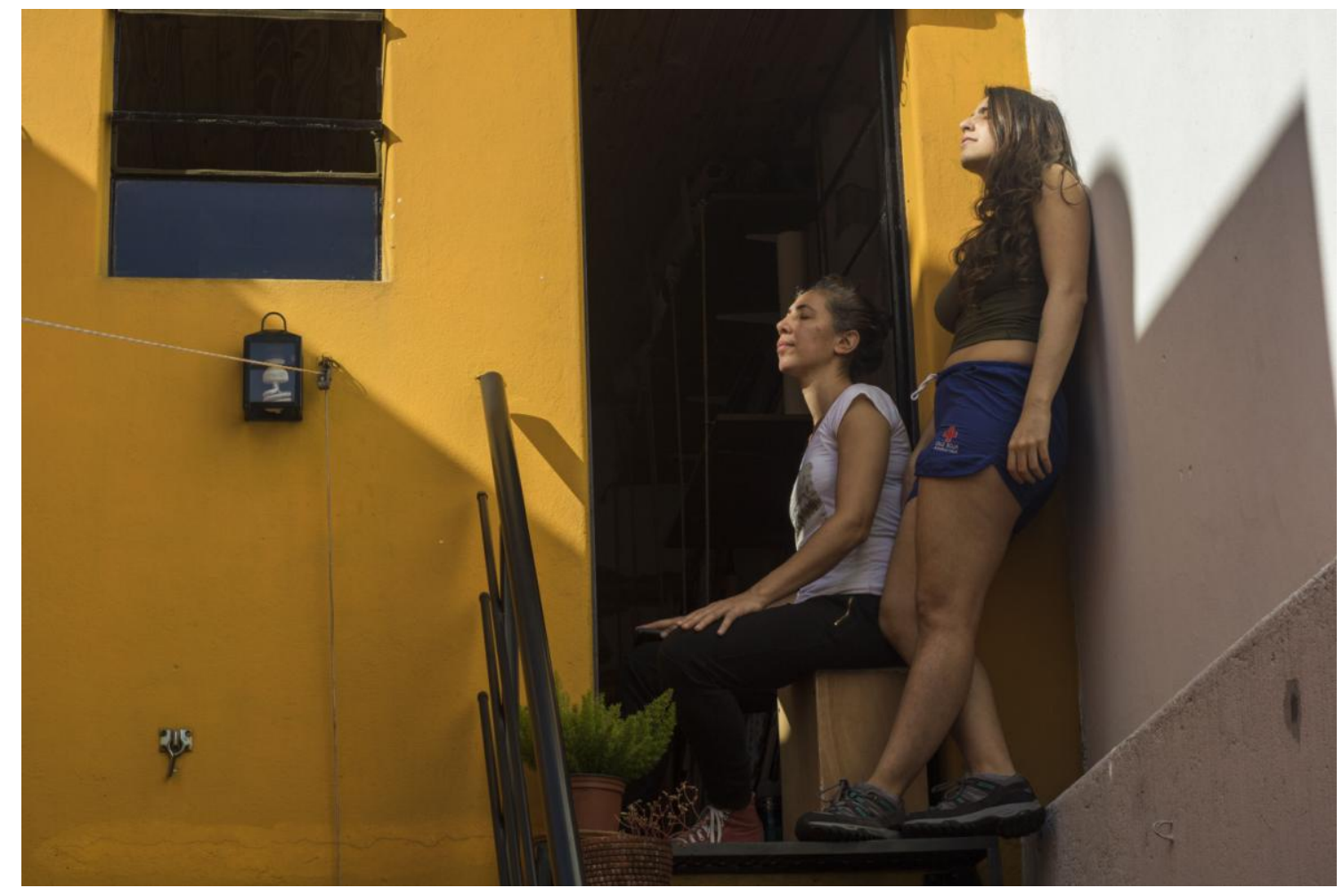




\title{
Las fotos sobre mis tiempos de aislamiento
}

\author{
hablan del pasado retratado,
}

pero también dicen deseos de futuro.

\begin{abstract}
"En ese espacio no cabe la nostalgia por "el tiempo de las cosas perdidas" sino más bien el qhipnayra uñtasis sarnaqapxañani: ese pasado que podría ser futuro, el que habita en nuestros sueños de presente. En lugar de nostalgia, hay más bien hacia el pasado un gesto colectivo de actualización celebratoria, de reapropiación paródica. La fiesta, el ritual, la caminata por vastos y accidentados territorios traen hasta nosotros al pasado viviente, actuante y sensible. Lejos de hacernos sufrir, estas imágenes nos energizan y emocionan: nos instan a explorar y a actualizar nuestras potencialidades utópicas" (Cusicanqui, 2015)
\end{abstract}




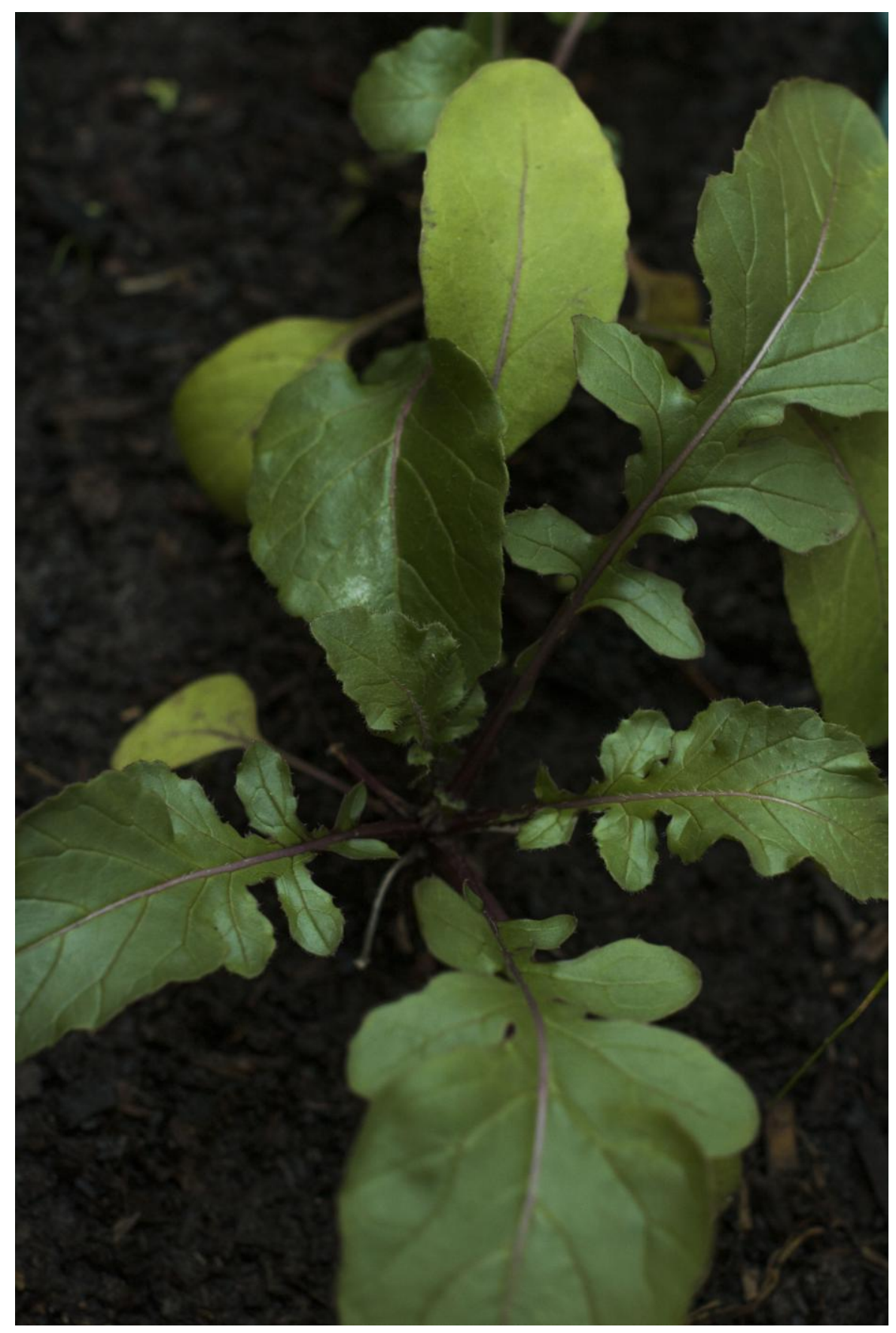

